\title{
COMMENT
}

\section{Commentary from the pediatric policy council 2018: the year of living dizzyingly}

\author{
Scott A. Rivkees ${ }^{1}$, Valerie Opipari ${ }^{2}$ and Scott Denne ${ }^{3}$ On behalf of the Pediatric Policy Council \\ Pediatric Research (2019) 85:115-117; https://doi.org/10.1038/s41390-018-0165-y
}

From the public policy vantage, the past year has been a dizzying cavalcade of political issues influencing children ranging from a high of increased federal support of the National Institutes of Health $(\mathrm{NIH})$ budget, ${ }^{1}$ to a low of separating children from immigrant parents, ${ }^{2,3}$ to the flip-flop related to the Children's Health Insurance Program, which expired for several months, then had an important bipartisan long-term fix, only to be followed with the recent threat of cuts. ${ }^{4,5}$

It is important to start with the basic premise that children are our nation's future to be cherished and given opportunities to succeed. In our country of more than 300 million individuals, nearly 100 million are of pediatric age, and each year, more than 4 million children are born in the United States. ${ }^{6}$ Because of their vulnerable, non-vocal, and non-voting nature, Americans from many different walks of life, including politicians, public servants, educators and parents have stood up for the rights and prosperity of the pediatric population. Health professionals have also taken the lead in advocating for children, as in the United States, there are more than 55,000 pediatricians ${ }^{7}$ and even a greater number of non-physicians dedicated to the medical care of children.

The Pediatric Policy Council (PPC) is the group that speaks on behalf of the major pediatric organizations, representing the Academic Pediatric Association, American Pediatric Society, Association of Medical School Pediatric Department Chairs, and Society for Pediatric Research. ${ }^{8}$ Over the past year the PPC, assisted by the Department of Federal Affairs of the American Academy of Pediatrics, has played a strong role in advocating for pediatric and academic causes. ${ }^{8}$ Over the past year, the PPC has participated in more than 50 letters that have been provided to Congress expressing our view on numerous issues critical to the health and well-being of children including CHIP reauthorization; ${ }^{4}$ court cases impacting the rights of lesbian, gay, bisexual, and transgender (LGBT) students; ${ }^{9}$ and the separation of immigrant children from their parents. ${ }^{2}$ The PPC has helped organize pediatric community responses to important issues, such as opposition to the repeal of the Affordable Care Act. Members of the PPC are also regular contributors to Pediatric Research through publication of monthly commentaries related to pertinent articles with policy implications.

Among the near constant feeling of anxiety coming from Washington, it is important to recognize important legislative changes of 2018 that have, and should continue to benefit children. Funding for the $\mathrm{NIH}$ increased by $\$ 3$ billion over the past year, following an increase of $\$ 2$ billion the previous year. ${ }^{1}$ Should the academic pediatric community see increased support for child health research, because of this increased funding, we can expect further improvements in child health and those diseases of adulthood whose origins begin in childhood. The impact of this increased funding is evident already as academic institutions are already feeling the benefit of this impact, with improving funding for investigators and the initiation of new pediatric-related research initiatives coming from the new leadership at the Eunice Kennedy Shriver National Institute of Child Health and Human Development (NICHD). ${ }^{10}$ Another positive development at $\mathrm{NIH}$ is the formation of the Trans-NIH Pediatric Research Consortium to coordinate pediatric research programs across its 27 institutes and centers. Led by the NICHD Director, Dr Diana Bianchi, this consortium will harmonize child health research efforts across the NIH and identify gaps and opportunities for collaboration. The effort will also serve to enhance communication between $\mathrm{NIH}$ advocacy groups and Capitol Hill, encourage senior pediatric researchers to serve on review panels, and work across NIH to support training to grow the pediatric workforce. ${ }^{11}$

Over 46 million children in the United States were enrolled in Medicaid and the Children's Health Insurance Program (CHIP) at some point in 2017. Although the eligibility criteria varies greatly in states and by age of the child, the federal minimum income eligibility for children is 138 percent of the federal poverty level (FPL) ( $\$ 28,000$ per year for a family of three). Depending on the state, children in families up to 400 percent of the FPL $(\sim \$ 81,000$ per year for a family of three) can qualify for Medicaid or CHIP. ${ }^{12-15}$ Thanks in large part to these two programs, $96 \%$ of children in the United States have health coverage, including the nation's most vulnerable children. Medicaid and CHIP cover $45 \%$ of infants, toddlers and preschoolers, $48 \%$ of children with disabilities or special health care needs, $80 \%$ of children who live at or near the poverty level, and $100 \%$ of children in foster care. After a fourmonth federal funding lapse, CHIP was finally renewed for ten years in March 2018. ${ }^{4}$ Just months after this major bipartisan success was secured, the White House proposed rescinding a portion of funding from CHIP, requiring advocates for children to mobilize quickly in opposition to any efforts to remove funds from this program. Thankfully, Congress did not advance this proposal, and CHIP's funding remains secure.

Over the past year, a clarion call was sounded over the potential repeal of the Affordable Care Act (ACA), which could have resulted in millions of Americans, including children, losing access to the healthcare they desperately need. This contentious issue triggered one of the broadest and loudest advocacy campaigns in the spring and summer of 2017 from the medical community, ${ }^{16}$ arguing against its repeal, culminating in a landmark vote in July 2017. Since this vote, the Administration has continued to sabotage the ACA by increasing the availability of less comprehensive plans that are not required to comply with the ACA,

${ }^{1}$ Department of Pediatrics, University of Florida, Gainesville, FL, USA; ${ }^{2}$ Department of Pediatrics, University of Michigan, Ann Arbor, MI, USA and ${ }^{3}$ Riley Children's Hospital, Indiana University, Indianapolis, IN, USA

Received: 7 August 2018 Accepted: 11 August 2018

Published online: 5 September 2018 
eliminating critical payments that help to stabilize the individual market, ${ }^{17}$ and slashing funding for outreach and enrollment efforts. ${ }^{18}$ Furthermore, we will also have to keep a watchful eye towards the potential adverse consequences related to skinny health plans, which do not meet Affordable Care Act quality standards and may influence pediatric coverage. ${ }^{19,20}$

Another national emergency looms before us with the exponential rise of deaths related to opioid abuse, as more than 42,000 Americans died from opioids in 2016, surpassing motor vehicle-related deaths. ${ }^{21,22}$ The pediatric impact of this epidemic is seen in the thousands of children exposed to opioids in utero, resulting in climbing rates of neonatal abstinence syndrome. ${ }^{23}$ Although declared a national emergency, we still need to work through strategies in preventing and dealing with this poisonous epidemic at a national level, as a clear national strategy to address this issue is lacking. ${ }^{24}$ Recognizing the importance of this issue, the PPC sponsored a plenary session at the Pediatric Academic Societies meetings in May 2018 on this topic.

There are several other critical issues related to children that have received less visibility, but are of paramount importance. These issues include poverty and inadequate education reform. It is estimated that more than 30 million children in the United States live in poverty, ${ }^{25,26}$ and it is well recognized that impoverished conditions stunt a child's opportunities. It is distressing that current administration has chosen to ignore the scope of the problem, as outlined in the recent United Nations report of poverty in the United States. ${ }^{25}$ We are also still faced with the lack of a concerted effort to improve the fate of children and families in poverty. There is also a major concern about efforts aimed at the reduction of school lunch program, which benefits 20 million children a year. ${ }^{27}$

The educational system in America has been a long-standing bellwether for opportunity. The benefit of preschool programs and after school programs is clear, along with programs that promote both childhood and adult literacy. ${ }^{28}$ Yet, talk about the importance of education has been subsumed by conversation about the need to provide funding for charter other private schools, which divert funding from the public sector. ${ }^{29}$ In 2018, we witnessed teachers in many states strike and protest over inadequate salaries, ${ }^{30}$ as many school teacher salaries are no longer sufficient to support a middle-class lifestyle. It is thus not surprising that many school districts are now struggling to find qualified teachers. ${ }^{31}$

Although we would like to believe that 2018 was unique in the scope and magnitude of mass killings at schools, ${ }^{32}$ sadly this was not the case. The more than 40 school shootings that occurred in 2018, wade in the tears of 288 school shootings that have occurred since $2009 .^{33}$ Although some states have enacted legislation to harden schools and put some limits on firearm sales, there is still no national strategy to address gun violence. It is disappointing that attempts to fully remove the legislative handcuffs from the Center of Disease Control and Prevention to study this issue have failed, ${ }^{34}$ yet we need to continue to advocate for possible solutions to this problem that have been proposed. ${ }^{35}$ While Congress did not do this, it included language indicating that Secretary Azar felt the federal government has the authority to fund gun violence research, a promising but small step forward. However, despite the apparent approval from Congress of such research, appropriators included no additional funding for gun violence research, without which the federal government will be unable to fund studies. Advocacy by the pediatric community will be necessary to continue to push for sustained funding to ensure that this long-dormant research area can be rebuilt.

We also face healthcare provider deficits in many disciplines resulting in inadequate care for expectant women and children. Huge physician deficits loom large in obstetrics, ${ }^{36,37}$ thus, it is not surprising that the United States has an unacceptably high child birth death rate $^{38}$ and relatively high rates of premature infant births. ${ }^{39}$ We are also witnessing an escalation in childhood behavioral and mental illness disorders, the tip of the iceberg of which being the unfortunately soaring pediatric suicide rate. ${ }^{40}$ The United States has about 8000 child psychiatrists, when more than 20,000 are needed. ${ }^{41,42}$ It is thus fitting that this issue of Pediatric Research has a major focus on the potential origins of neurological and psychiatric diseases.

Over the next year, there will be the predictable pediatric causes that warrant our attention and advocacy. These will include continued advocacy in support of research to cure pediatric disease, the need to ensure that children have proper healthcare funding, the need to ensure that children can learn in a safe environment, and the need to ensure that children do not go to bed hungry. However, as we have learned over the past year, there will be the unpredictable political issues that will impact children, requiring us to quickly mobilize and stand with a collective voice on their behalf.

Among the subsuming political buzz of this past year, we can see what happens when the country stands up for children. The reversal of the child separation policy followed a trumpet blare of the outrage over this policy. ${ }^{2,43}$ However, as we are now witnessing $^{44}$ and will predictably see in the fate of the children, there will be sad consequences from even just short-term childharming policies, ${ }^{3}$ meaning that we need to be continuously vigilant and on guard as pediatric care providers. While this was an important victory in child health advocacy efforts, it is clear there is still much more to do as the health and future of our nation depends on and is reflected in the policies we support that impact child health. Lastly, it is important that all of us as parents, leaders, and professionals, do all that we can to replace the dizzying vitriol that is engulfing our country and spilling over onto our children ${ }^{45}$ with decency that has long been the bedrock of our society. ${ }^{46}$

\section{ADDITIONAL INFORMATION}

Competing interests: The authors declare no competing interests.

Publisher's note: Springer Nature remains neutral with regard to jurisdictional claims in published maps and institutional affiliations.

\section{REFERENCES}

1. Kaiser, J. Final 2018 budget bill eases biomedical researchers' policy worries. http://www.sciencemag.org/news/2018/03/final-2018-budget-bill-easesbiomedical-researchers-policy-worries. Accessed on 22 March 2018.

2. Rivkees S. A., From the Pediatric Policy C 2018 cherishing family values: let us not let immigration policy harm children. Pediatr Res. in press.

3. Danaher, F. The suffering of children. N. Engl. J. Med. 379, e4 (2018).

4. Henry J. Kaiser family foundation summary of the 2018 CHIP funding extension. https://www.kff.org/medicaid/fact-sheet/summary-of-the-2018-chip-fundingextension/. Accessed on 24 January 2018.

5. Kaiser Health News. 4 takeaways from Trump's plan to rescind CHIP funding. https://khn.org/news/4-takeaways-from-trumps-plan-to-rescind-chip-funding/. Accessed on 14 May 2018.

6. The Annie E Casey Foundation. The changing child population of the United States. Analysis of data from the 2010 census. http://www.aecf.org/resources/thechanging-child-population-of-the-united-states/. Accessed on August 7, 2018.

7. American Academy of Pediatrics. Frequently asked questions. Pediatric workforce. https://www.aap.org/en-us/professional-resources/Pediatrics-as-a-Profess ion/Pages/Frequently-Asked-Questions.aspx. Accessed on 25 June 2018.

8. Pediatric Policy Council. https://www.aps-spr.org/about/shared-vision/pediatricpolicy-council.asp. Accessed on August 7, 2018.

9. Williams, P. Supreme court rejects Gavin Grimm's transgender bathroom rights case. https://www.nbcnews.com/news/us-news/u-s-supreme-court-rejects-transg ender-rights-case-n729556. Accessed on August 7, 2018.

10. NIH names Dr. Diana Bianchi director of the National Institute of Child Health and Human Development. https://www.nih.gov/news-events/news-releases/nihnames-dr-diana-bianchi-director-national-institute-child-health-humandevelopment. Accessed on 25 August 2016

11. New Trans NIH consortium aims to advance pediatric research on a global level. https://www.nih.gov/news-events/news-releases/new-trans-nih-consortiumaims-advance-pediatric-research-global-level. Accessed on 13 June 2018. 
12. Henrey Kiaser Family Foundation. Where are states today? Medicaid and CHIP eligibility levels for children, pregnant women, and adults https://www.kff.org/ medicaid/fact-sheet/where-are-states-today-medicaid-and-chip/. Accessed on 28 March 2018.

13. Henry Kaiser Family Foundation. Medicaid and CHIP income eligibility limits for children as a percent of the federal poverty level. https://www.kff.org/healthreform/state-indicator/medicaid-and-chip-income-eligibility-limits-for-childrenas-a-percent-of-the-federal-poverty-level/. Accessed on 1 January 2018.

14. Georgetown University Center for children and families Medicaid Fact Sheets. https://ccf.georgetown.edu/2017/03/03/medicaid-fact-sheets/.Accessed on 3 March 2017.

15. Henry J. Kiaser Foundation. Total Medicaid spending. https://www.kff.org/ medicaid/state-indicator/total-medicaid-spending/?currentTimeframe $=0 \&$ sortM odel=\%7B\%22colld\%22:\%22Location\%22,\%22sort\%22:\%22asc\%22\%7D. Accessed on August 7, 2018.

16. Mangan, D. American Medical Association opposes Obamacare repeal bill, citing coverage losses by millions of Americans. https://www.cnbc.com/2017/09/19/ groups-line-up-to-oppose-gop-obamacare-repeal-bill-as-deadline-looms.html. Accessed on 19 Sept 2017.

17. Martin, K. Trump freezes Affordable Care Act payments https://www.foxbusiness. com/markets/trump-cuts-affordable-care-act-payments-raising-premiums-andendangering-health. Accessed on 9 July 2018.

18. Morse, S. CMS cuts Affordable Care Act Navigator funding from $\$ 36$ to $\$ 10$ million. https://www.healthcarefinancenews.com/news/cms-cuts-affordable-careact-navigator-funding-36-10-million. Accessed on 11 July 2018.

19. Pear, R. New Trump rule rolls back protections of the affordable care act. https:// www.nytimes.com/2018/06/19/us/politics/trump-affordable-care-act-healthinsurance.html. Accessed on 19 June 2018.

20. Resource page: emerging themes in state medicaid waivers https://urldefense. proofpoint.com/v2/url?u=https-3A_www.chcf.org_project_resource-2Dpage2Demerging-2Dthemes-2Dstate-2Dmedicaid-2Dwaivers_-23syntheses\&d=DwIF$\mathrm{g} \& \mathrm{c}=\mathrm{pZJ}$ PUDQ3SB9JplYbifm4nt2IEVG5pWx2KikqINpWIZM\& $\mathrm{r}=\mathrm{v}-\mathrm{cR} 2 \mathrm{Rrz} 1 \mathrm{paVHu}$ gYC-2Q5g\&m=pRwhl3XdFQotRHg-f9Un0S4-6Y30GOTBGQKovuXDcW0\&s=im 14U3dGn3snJJAhyTEyCm6N50tYEwuSJeB7sz-8nTM\&e=. Accessed on 2 March 2018.

21. NIDA Press Office. Nearly half of opioid-related overdose deaths involve fentanyl. https://www.drugabuse.gov/news-events/news-releases/2018/05/nearly-halfopioid-related-overdose-deaths-involve-fentanyl. Accessed on 1 May 2018.

22. Mahoney, G. Deaths from Opioid overdoses now higher than car accident fatalities. https://www.healthline.com/health-news/deaths-from-opioid-overdos es-higher-than-car-accident-fatalities\#1. Accessed on 30 March 2018.

23. Wachman, E. M., Schiff, D. M. \& Silverstein, M. Neonatal abstinence syndrome: advances in diagnosis and treatment. JAMA 319, 1362-1374 (2018).

24. Though White House. President Donald J. Trump's initiative to stop opioid abuse and reduce drug supply and demand. https://www.whitehouse.gov/briefingsstatements/president-donald-j-trumps-initiative-stop-opioid-abuse-reduce-drugsupply-demand/. Accessed on 19 March 2018.

25. Report of the Special Rapporteur on extreme poverty and human rights on his mission to the United States of America. http://undocs.org/A/HRC/38/33/ADD.1. Accessed on 4 May 2018.

26. National Center for Children in Poverty. Child poverty http://www.nccp.org/ topics/childpoverty.html. Accessed on August 7, 2018.

27. Meyer, B. Betsy DeVos and Republicans plan to cut free and reduced lunch programs. http://affinitymagazine.us/2017/02/24/betsy-devos-and-republicansplan-to-cut-free-and-reduced-lunch-programs/. Accessed on 24 February 2017.
28. Landry, S. H., Swank, P. R., Smith, K. E., Assel, M. A. \& Gunnewig, S. B. Enhancing early literacy skills for preschool children: bringing a professional development model to scale. J. Learn Disabil. 39, 306-324 (2006).

29. Ladd, H. F. and Singleton, J. D., The fiscal externalities of charter schools: Evidence from North Carolina (April 9, 2018). Economic Research Initiatives at Duke (ERID) Working Paper No. 261. Available at SSRN: http://www.ssrn.com/abstract=3082968 or https://doi.org/10.2139/ssrn.3082968. Accessed on August 7, 2018.

30. Behind the teacher strikes that have roiled five states. https://www.economist. com/united-states/2018/05/05/behind-the-teacher-strikes-that-have-roiled-fivestates. Accessed on 5 May 2018.

31. Gaines, L. Trying to bridge the teacher shortage gap. http://www.wbur.org/ hereandnow/2018/07/23/teacher-shortage-gap-illinois. Accessed on 23 July 2018

32. S. Ahmed and C. Walker. There has been, on average, 1 school shooting every week this year. https://www.cnn.com/2018/03/02/us/school-shootings-2018-listtrnd/index.html. Accessed on 25 May 2018.

33. Grabow, C., and Rose, L. The US has had 57 times as many school shootings as the other major industrialized nations combined. https://www.cnn.com/2018/05/21/ us/school-shooting-us-versus-world-trnd/index.html. Accessed on 21 May 2018.

34. Kaplan, S. Congress quashed research into gun violence. Since then, 600,000 people have been shot. https://www.nytimes.com/2018/03/12/health/gunviolence-research-cdc.html. Accessed on 12 March 2018.

35. William W., Sullivan S. House budget says CDC can study gun violence. https:// www.washingtonpost.com/news/to-your-health/wp/2018/03/22/house-budgetsays-cdc-can-study-gun-violence/?noredirect=on\&utm_term =.f1c43bc247e1. Accessed on 22 March 2018.

36. Kirch, D. G. \& Petelle, K. Addressing the physician shortage: the peril of ignoring demography. JAMA 317, 1947-1948 (2017).

37. Doximity 2017 new research details risk of national OB-GYN shortage. https:// www.doximity.com/press_releases/new_research_details_risk_of_national_ob-g yn_shortage. Accessed on August 7, 2018.

38. Young, a. Hospitals know how to protect mothers. They just aren't doing it. https://www.usatoday.com/in-depth/news/investigations/deadly-deliveries/ 2018/07/26/maternal-mortality-rates-preeclampsia-postpartum-hemorrhagesafety/546889002. Accessed on 27 July 2018.

39. March of Dimes. 2016, premature birth, reportcard. https://www.marchofdimes. org/materials/premature-birth-report-card-united-states.pd. Accessed on August 7, 2018.

40. National Center for Injury Prevention and Control. Suicide rising across the US https://www.cdc.gov/vitalsigns/suicide/index.html. Accessed on 11 June 2018.

41. American Board of Psychiatry and Nerorolgy, Inc. https://www.abpn.com/. Accessed on August 7, 2018.

42. American Academy of Child and Adolescent Psychiatry. https://www.aacap.org/ aacap/resources_for_primary_care/Workforce_Issues.aspx. Accessed on August 7 , 2018.

43. Gonzales R. Sessions says 'zero tolerance' for illegal border crossers, vows to divide families. https://www.npr.org/sections/thetwo-way/2018/05/07/609225 537/sessions-says-zero-tolerance-for-illegal-border-crossers-vows-to-dividefamilies. Accessed on 7 May 2018

44. Sanders, T., and Grabell, M. https://www.propublica.org/article/worker-chargedwith-sexually-molesting-eight-children-at-immigrant-shelter. Accessed on 2 August 2018.

45. Damon W. The children at the Trump rallies. https://www.nytimes.com/2018/08/ 03/opinion/trump-rally-maga.html. Accessed on 3 August 2018.

46. Freeman, M. Decency. The bonfire of the vanities https://www.youtube.com/ watch?v=2KbsZ2UFw8o. Accessed on August 7, 2018. 